\title{
A QUALITY FUNCTION DEPLOYMENT METHOD APPLIED TO HIGHLY REUSABLE SPACE TRANSPORTATION
}

\author{
Edgar Zapata \\ National Aeronautics and Space Administration \\ Kennedy Space Center, Fl 32899
}

(407) 861-3955

\begin{abstract}
$\underline{\text { Abstract }}$
This paper will describe a Quality Function Deployment (QFD) currently in work the goal of which is to add definition and insight to the development of long term Highly Reusable Space Transportation (HRST). The objective here is twofold. First, to describe the process, the actual QFD experience as applies to the HRST study. Second, to describe the preliminary results of this process, in particular the assessment of possible directions for future pursuit such as promising candidate technologies or approaches that may finally open the space frontier. The iterative and synergistic nature of QFD provides opportunities in the process for the discovery of what is key in so far as it is useful, what is not, and what is merely true. Key observations on the QFD process will be presented. The importance of a customer definition as well as the similarity of the process of developing a technology portfolio to product development will be shown. Also, the relation of identified cost and operating drivers to future space vehicle designs that are robust to an uncertain future will be discussed. The results in particular of this HRST evaluation will be preliminary given the somewhat long term (or perhaps not?) nature of the task being considered.
\end{abstract}

\section{INTRODUCTION}

Any discussion on what makes access to space today an infrequent multi-million (or billion) dollar affair is as likely to bring out the most major of grievances as it is to emphasize the most minor of causes. If there are in fact a "significant few causes" out there waiting to be discovered then a QFD or Quality Function Deployment method is the way to ferret them out. More importantly, dramatic improvements in the affordability and responsiveness of launch systems will not lag too far behind. Current planning for the future in the aerospace world is focusing on the balancing act of reducing costs to develop, make, buy and operate high flight rate launch systems. This is embodied somewhat in the X-33 and Reusable Launch Vehicle program, possible successors to the Shuttle fleet. Looking beyond the RLV cost possibilities and to the day of really cheap and routine access to space takes us to very far term planning in a world that holds abundant possibilities. Highly reusable space transportation is one of these possibilities. For robust planning, methodical, well structured approaches such as QFD are a must.

QFD, a method pioneered by the Japanese in the late 60 's, works to communicate the language of the consumer into the language of designers. From there, design targets for improvement are set. Immediately, one might conclude the notion of consumers is for the most part not relevant to the business of launching payloads to orbit, or at the least the situation is not at all similar to a person in the market for a new VCR. This perception is entirely incorrect. One need simply see the consumer as "customer" to begin to see the use of QFD in aerospace. Previous work in the field of QFD as applied to space transportation (Bray 1993 and Dankhoff and Hope 1993) has focused on strategic planning. The objective of this paper is to present on going work in this field in particular as regards defining the technical characteristics or features of a highly reusable space transportation system.

\section{Who is the Customer in the Launch Business Today?}

Customer definition is an extremely important part of any successful business. The notion has even been incorporated into the recent focus of the federal government at "reinventing" itself. While the notion of a collective, generalized taxpayer that seeks maximum efficiency may be comforting, it is not an idea that lends itself to further detailing the all important "customer wants". In fact, one concept alone may be insufficient to define the launch business customer. 
One immediate idea may be to consider the payload provider as the ultimate customer. A Hughes, IntelSat or NASA payload customer can embody and communicate the attributes most wanted in tomorrow's launch systems. Low cost, standard interfaces, the size and weight ranges desired as well as the ease of making the arrangements with the launch provider are all paramount in the payload providers organization. The customer can even be one step removed from this process, such as a cable TV provider, delegating all the interfacing to the satellite builder.

There is another customer to consider which is an especially important part of communicating requirements to designers - the operator. While a payload provider can express a desire for lower costs to orbit it is an expression more similar to a passenger on a trip to Bermuda. The size of the compartments for overhead luggage, the comfort of the seat, the trouble for ticketing, the ticket price and being on time are the concerns. "How" to achieve satisfaction of these wants is entirely another matter which bring us to the customer as the operator of the transportation system. While a customer survey may help refine areas for renewed focus in cabin comfort a close collaboration between an airline operator, such as American Airlines, and a designer and manufacturer, such as Boeing, will provide far more results overall in the direction of reducing costs and increasing reliability, fleet productivity and flight rates.

Still another customer is the resource provider. This may be embodied in a program manager, for the case of government funding, or in an investor, such as a private enterprise. Again broad goals such as $\$ 100$ per pound of payload to orbit, new markets or high flight rates may be communicated. Eventually, "how" to achieve these goals will fall to designers, manufacturers and operators working in close collaboration. QFD provides the method for this communication of diverse customer requirements as well as a method for structuring the collaboration of all parties to the production process, including technology development.

QFD demands this customer definition. One such area in work involves the goals of the Highly Reusable Space Transportation project being funded by NASA. A QFD is successfully being used to define the direction for tomorrow's space transportation. First, the customer definition requires the involvement of operators. For operational experience Shuttle system engineers at the Kennedy Space Center can serve as part of the voice of the customer, an especially important one. A NASA program manager, expressing the broader goals of the agency, is also customer, helping to define what is wanted in the next generation of space transportation. Finally, diverse backgrounds from NASA, industry and academia including manufacture, costing, research, managers and future technologies round off the customer definition. Further, a complete QFD communicates with designers and technologists, learns from demonstration, and continuously improves on previous targets.

\section{What are the "Wants" for Future Space Transportation?}

Defining those qualities that are desirable in a future space transportation system may seem a simple matter. Low cost. Higher flight rate. What more is there to it? It is often assumed that a full understanding exists among decision makers or designers of what "low costs" mean. Further it may be thought that processes such as QFD over complicate the matter. Awareness of the actual simplicity and power of the QFD approach typically comes only with experience given the sometimes daunting nature of the interrelated charts and steps used in QFD. In aerospace the long time emphasis on specifications and compartmentalization of experience has meant QFD, with a more topto-bottom design approach, has not been adopted for widespread use.

A QFD approach for launch systems must begin with an understanding of "wants". Work toward highly reusable space transportation is using this approach. A diverse group of aerospace professionals from industry, government and academia has tackled the problem of defining those qualities most desirable in a future launch system. This group is the Space Propulsion Synergy Team (SPST). This work has not been done in a vacuum, but traces back to the Penn State call to arms in 1990 and the subsequent formation of the Space Propulsion Synergy Group (Bray 1993 and Dankhoff and Hope 1993).

The wants of the future of the U.S. launch industry cover three basic areas, R\&D, program acquisition, and operations. QFD calls these "wants" quality demands or "what's". For our purposes we have adopted calling them desirable attributes. For example, in operations, the attributes are as follows: affordable, dependable, responsive, safe, environmentally compatible and having public support. There are subsets of these assigned and even third level qualities. All this is geared around more clearly expressing customer desires. 
The task of defining wants does not end here. The question of priorities is next. Again, the QFD process provides the structured, step by step approach that will provide the community of developers, designers, manufacturers and operators with insights that are key to improvement. Take for example the priority of the quality demand "ease of integration". This attribute is an expression of the manpower required in current launch systems such as Shuttle to mate, put together, connect or attach a host of systems. While for a single stage system the concern may appear mostly resolved it is actually far from it. The demanded quality addresses not only the attachment of an orbiter to an external tank but a slew of other activities such as mating hydrogen vent arms, propellant umbilicals and even launch platforms to facilities. All the latter of which are relevant to even SSTO's.

The priority is established by considering not only the importance of improvement in this area but also by asking two questions: (1) where are we today as far as ease of integration and (2) where do we want to go? This is done for all the demanded qualities. The result is a series of weighted priorities.

The expression and defining of desirable attributes, weighted in order of priority, is a start but it is not yet a useful set of expressions. The attributes or quality demands have not yet been translated into design targets or even into meaningful measures. A design approach (Akao 1988) has not been defined. This takes us to the "How" stage of QFD.

\section{"How" do we Design for Low Cost and Operability?}

Having defined the qualities we want most from a highly reusable system the next task of a QFD is to assign measurable criteria to these areas. In QFD jargon these criteria are called "quality characteristics". They are key to eventually manifesting the desired attributes in a design. This step here goes from the qualitative to the quantitative. While the task of assigning quantities to attributes such as reliability or low operations cost may seem simple it is important to keep in mind that the "hows" are in essence guides for the product that is being developed. To say " $\$ 100 / 1 b "$ as a measurable quantity of affordable launch operations does not bring us to manifesting in a design the characteristics that will get us there. QFD does eventually set such targets but we err if this jump from what we want to more measurable quantities skips the all important step of defining "how"?

This prior point hits upon the taboo subject of instructing developers on what to develop or designers on how to design. The intermingling of the research versus applications or operations oriented technical communities is often a difficult affair. Setting "design to" goals for a project is currently advocated as a preferred decision making approach in some management schools of thought. This is based on the desire to avoid boxing in the creative potential of a product developer. This approach, though it may work, overlooks a few important details. Eventually somewhere in the product development stage someone must figure out "how" to achieve the established goals. Also, for far term endeavors, knowing how to evaluate the likelihood that a developer, or a certain product one is being sold, will meet one's goals is a key part of making informed "purchases". QFD fills in the gaps between the desirable attributes a customer wants (affordable, creating new markets) and the goals $(\$ 100 / \mathrm{lb})$ that are set. In fact, it goes one step further and aids in understanding what the numeric goals of an operator or a project manager or an R\&D effort should be.

The need for operator involvement can not be stressed enough. This is as basic as the close collaboration required between a designer and the manufacturing department. Customer definition must be broad and go well beyond near term deadlines, funding profiles or requirements for payload weight and size. The definition of "wants", previously outlined, and the all important determination of "how" demands this cross cutting collaboration of multiple disciplines from technology R\&D to design to manufacture to operations.

A case in point is the QFD for highly reusable space transportation. A simple measurable quality characteristic is the "number of different fluids in the system both flight and ground". It is related to the desirable attribute of dependability. Dependability encompasses reliability as well as the ability to launch on time every time. While this is certainly true it is with a QFD process that the quality characteristic is given context. Each of the criteria that are determined are cross correlated to all of the desirable attributes. A scoring process using individuals with diverse and relevant backgrounds is performed - what is referred to as "having a QFD session". Discussion even to the level 
of heated debate is a critical component of a QFD as is having a facilitator. A rough consensus on relations between measurable quantities and qualities is one valuable outcome.

Consider the relation of the "number of toxic fluids" to those attributes of future launch systems that we wish to improve. Aircraft like operations, much higher reliability, and much reduced costs will correlate strongly with a reduction in the number of toxic fluids versus those used today in an operation such as Shuttle. This insight is gained in the QFD discussion and scoring process. Eventually a matrix is built that establishes relationships between "what" and "how", between our desirable attributes and our measurable criteria.
- Strong Correlation
Average Correlation
$\triangle$ Some Correlation

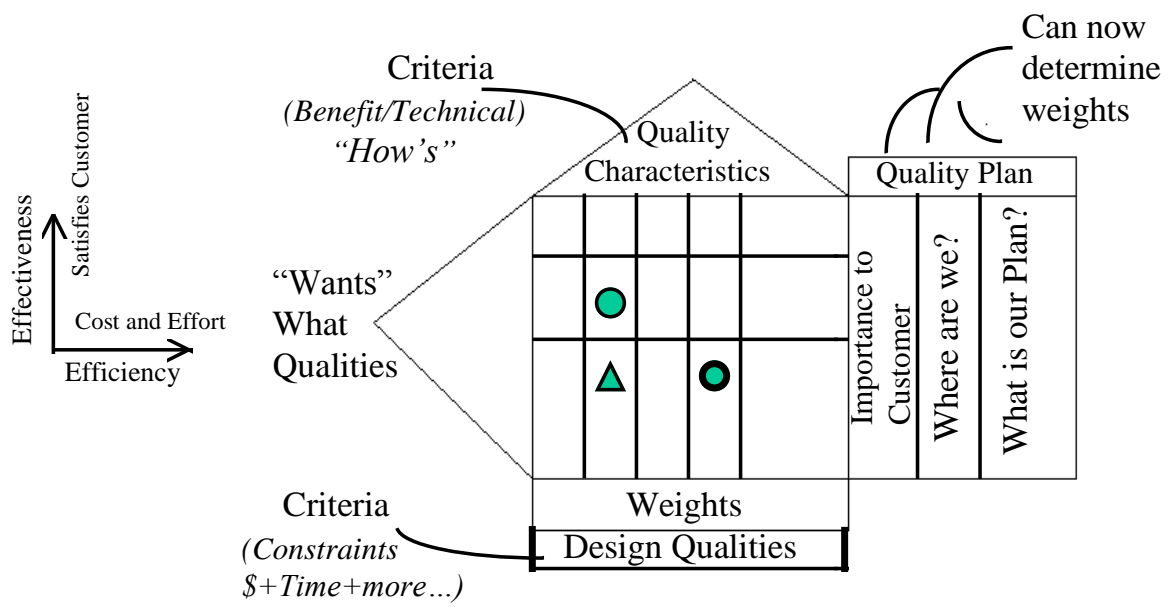

FIGURE 1. The House of Quality Summarized as Adopted to the SPST Use.

\section{The Strength of the Process:}

There lies the strength of this process, measurable criteria are systematically related to the high level, but vague, qualities such as being affordable to operate or being robust. In recent QFD work performed by the Space Propulsion Synergy Team, one top criteria, a critical "how" to achieving dramatic affordability gains in reusable launch systems, was to "reduce the number of different fluids". Also, a reduction in the "number of toxic fluids" as a separate criteria has currently been identified as a "Top 10" requiring focus and emphasis in future designs as well as R\&D.

Shuttle is an excellent baseline for improvement given it is the only somewhat reusable launch vehicle in existence. A list of toxic fluids would include hypergols for orbital maneuvering systems, both $\mathrm{N} 204$ and $\mathrm{MMH}$, and hydrazine for auxiliary power units. Freons and ammonia for avionics thermal management, and waterproofing agents for thermal protection system tiles add to the list of principals. The use of precision cleaning agents would add further. By one count the number would be 10 .

Now the idea of design targets is introduced, without having skipped the task of identifying through a QFD what requires emphasis in the first place. A design for improvement might target a vehicle with no more than 2 or 3 toxic fluids, a greater than $50 \%$ improvement.

Already, designs such as the recently selected X-33 Reusable Launch Vehicle (RLV) advanced technology demonstrator are manifesting design features that improve on criteria surfaced as key using QFD processes. It is an increasing consensus in the technical community that such criteria are vital and must be manifested in future designs. 
The move to $\mathrm{O} 2 / \mathrm{H} 2$ based reaction and orbital maneuvering systems eliminates two toxic fluids as well as reducing the number of different fluids. The growing assumption that future systems will use electromechanical actuators responds to "reducing the number of different fluids" by eliminating hydraulics (assuming a non-toxic power source). The X-33 incorporates both of these into it's demonstration package.

Not all the QFD surfaced relations between desirable system attributes and measurable quality characteristics are as simple to baseline and hence to set new targets for as the examples given. The need to determine these baselines and to set design targets is a top priority for the aerospace community that will work on or influence the direction of highly reusable space transportation systems. Still other top criteria are simple to baseline and improve upon but the relation to the benefits to be gained has not been clearly understood. An improvement in effective Isp such as a doubling over conventional rocket systems has an established relation to reduced mass fractions which will likely relate strongly to operability gains that otherwise would have been limited by weight concerns. Yet the exact nature of these relations needs further study.

Still other criteria may be considered in QFD only to find later that the criteria is not useful - it is merely true. A mathematician would refer to this as a trivial result such as after having spent many pages on an integral only to find that $\cos x=\cos x$. True, but not the answer we were looking for. For example, the criteria "\$ per day of delay" may seem to be very much related to the cost of operating a system and to it's life cycle cost. The more important question to ask is: Does this criteria communicate a feature into the design or to the product developer or is it a result of features? If no and yes, such criteria are dropped from further use. In this way the eventual prioritized list of "how" (measurable criteria) is one that can be targeted for improvement and manifest in a design as a physical feature or implementation.

\begin{tabular}{|c|c|c|c|c|c|c|c|c|c|}
\hline & & & ivironmental & Saf & & & & & \\
\hline $\begin{array}{c}\text { QFD Chart for } \\
\text { Highly Reusable Space } \\
\text { Transportation } \\
\text { (Operational Phase) }\end{array}$ & 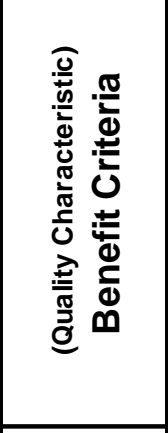 & 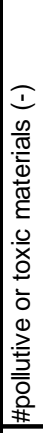 & 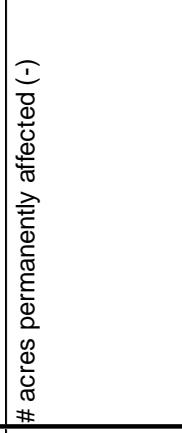 & 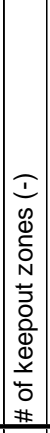 & 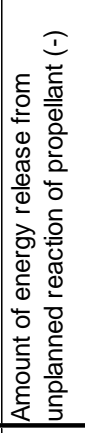 & 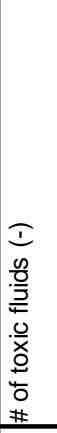 & 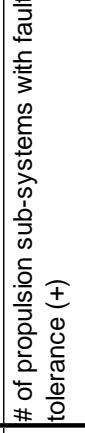 & 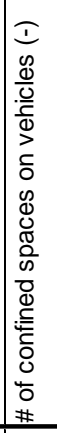 & 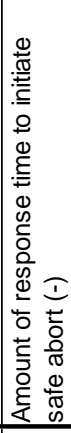 \\
\hline (Demanded Quality) & List Number & 1 & 2 & 3 & 4 & 5 & 6 & 7 & 8 \\
\hline Attributes & SCORE & & & & & & & & \\
\hline $\begin{array}{l}\text { Affordable / Low Life Cycle Cost } \\
\text { Low Recurring Cost }\end{array}$ & & & & & & & & & \\
\hline Low Cost Sens. to Flt. Growth & 1.83 & & & & & & & & \\
\hline Operation and Support & 11.44 & & & & & & & & \\
\hline Initial Acquisition & 4.12 & & & & & & & & \\
\hline Vehicle/System Replacement & 4.12 & & & & & & & & \\
\hline $\begin{array}{l}\text { Dependable } \\
\text { Highly Reliable } \\
\text { Intact Vehicle Recovery }\end{array}$ & 2.29 & & & & & & & & \\
\hline
\end{tabular}

FIGURE 2. Portion of a QFD Matrix 


\section{Costs and Functions:}

QFD can also be used further. In fact, it is incomplete without considerations of the functions to be achieved as well as the costs or risks of a new product development. Suffice it to say, what we in aerospace call the programmatics of a project lends itself ideally to a "cost deployment". Establishing functions, the performance aspect of a system, can also be understood using a "function deployment" (Akao 1988).

The functions that a spaceplane may achieve have too often been the majority emphasis in developing advanced systems. Hence the public analogies of a Shuttle to an Indy race car. By consideration of the benefits wanted in a future system as well as true customer definition a proper balance can be returned to extremely complex, large and long term technical projects.

\section{The Future of QFD and Space Transportation:}

In recent years the use of QFD methods has played a significant role in defining future space transportation. Basic relationships between the qualitative "pie in the sky" goals we want and the quantitative measures that tell us how to get there are being understood and communicated through out the technical community. In turn, the process brings together synergistically the required groups of diverse backgrounds. This is required to broadly understand the whole picture of where we are today in launch systems as products and "what" and "how" we must do tomorrow's highly reusable, affordable systems.

It is unlikely that the reusable space transports to come will in any way be much more affordable than Shuttle if the relations between our goals and our design features are never clearly understood. QFD processes allow this understanding to occur and if one day this understanding is manifest in a spaceplane of tomorrow then we will have begun to open the space frontier.

\section{$\underline{\text { Acknowledgments }}$}

The author acknowledges the Space Propulsion Synergy Team he is privileged to participate in. This includes numerous members: Jim Bray of Lockheed Martin, Ray Byrd of Boeing, Ed Cady of McDonnell Douglas, George Cox of Pratt and Whitney, Walt Dankhoff, the Executive Secretary of the SPST, Ron Hankins of Aerojet, Robert Houston of Lockheed Martin, Dan Levack of Rocketdyne, Carey McClesky of NASA KSC, Earl Pansano of Lockheed Martin, Russel Rhodes of NASA KSC, John Robinson of PST Co., Rick Vargo of McDonnell Douglas and Gordon Woodcock of Boeing. The guidance offered by the NASA HRST project team, Joe Howell of NASA MSFC and John Mankins of NASA HQ, is also acknowledged.

\section{$\underline{\text { References }}$}

Akao, Yoji (1988) "Quality Function Deployment: Integrating Customer Requirements into Product Design," [Translation from "Hinshitsu tenkai katsuyo no jissai" by Glenn H. Mazur], Productivity Press, Portland, OR., 4: 164-165.

Bray, Jim (1993) "Payoffs for Applying QFD Techniques in the SPSG Strategic Planning Support Effort for ETO Transportation and Propulsion Systems," in AIAA/SAE/ASME/ASEE 29th Joint Propulsion Conference and Exhibit, June 28-30, 1993, Martin Marietta Manned Space Systems, New Orleans, LA.

Dankhoff, Walter F., and Hope, William P. (1993) "Overview of the Space Propulsion Synergy Group (SPSG) Strategic Planning Support Efforts for Earth to Orbit Transportation," in AIAA/SAE/ASME/ASEE 29th Joint Propulsion Conference and Exhibit, June 28-30, 1993. 